\title{
The impact of enterprise risk management on institutional performance in Jordanian public shareholding companies
}

\author{
Mohammad Altanashat \\ Maged al Dubai \\ Sadun Alhety \\ Finance and administrative college \\ Almadinah International University Shahalam Malaysia
}

\section{Key words}

Balances scorecard, enterprise risk management (ERM), institutional performance

\begin{abstract}
This study examined the impact of Enterprise Risk Management (ERM) on institutional performance of public shareholding companies in Jordan based on COSO (2004) ERM Integrated Framework. Questionnaire survey was adopted as the research methodology for this study, and a total of 313 questionnaires were successfully collected. The obtained data was analyzed by Structural Equation Modeling Tool (Smart-PLS), and based on the analysis, implementation of ERM was found to have a significant influence on institutional performance. From the finding's analysis, it was revealed that enterprise risk management framework had a role in improving the performance of extraction companies in Jordan. The analysis also highlighted that the increase of enterprise risk management framework implementation will increase the performance of the extraction companies in Jordan. Furthermore, all the independent variables (Internal Environment, Event Identification, Risk Assessment, Risk Response, Control Activities, Information and Communication, and Monitoring) are significant predictors, except for objective setting. These variables statistically and significantly predicted performance of extraction companies in Jordan. The findings from this study enable organizations to better understand the status of their ERM implementation and assist them in identifying areas of improvement, with regards to the processes within each ERM elements.
\end{abstract}

Corresponding author: Mohammad Altanashat

Email addresses for the corresponding author: altanashat.mohammad@yahoo.com

First submission received: $5^{\text {th }}$ May 2018

Revised submission received: $20^{\text {th }}$ July 2018

Accepted: $8^{\text {th }}$ August 2018

\section{Introduction}

A variety of risks confronts organizations today. Forces such as globalization, regulatory uncertainty, competition and technology add complexity to the business environment, thereby imposing additional risks on the economic entity, and ultimately, decreasing shareholder value. Given these risk factors and others, managers have to achieve a more holistic orientation towards risk management and stronger governance in their organizations (Shannak, 2010). In order to be able to face the complex internal and external challenges of the modern world, a firm's investment in an Enterprise Risk Management (ERM) program is no longer a matter of choice, but of necessity. Poor risk management is found to be a major contributor to the credit crisis, and consequently an increasing number of shareholders, Boards of Directors (BOD) and rating agencies are taking a serious view of and analytical approach to adopting risk management (Shoter, 2016). The word enterprise for Enterprise Risk Management (ERM) clearly shows a different meaning than traditional Risk Management. Enterprise means to integrate or aggregate all types of risks, using integrated tools and techniques to mitigate the risks and to communicate across business lines or level compared to Traditional Risk Management (Izah, Tahir, Ahmad, 2011). In recent years, a shift of trend has been observed on how the organizations view and manage risks (Shad, Lai, \& Iskandar, 2015) as a fundamental concern of any organization. Instead of the traditional risk management method, which is based on the silo approach, organizations now treat risk management from a holistic perspective which is commonly known as Enterprise Risk Management 
(ERM) (Gordon, Loeb, Tseng, 2009). The instability in the international financial, currency and commodity markets, and uncertainties on the direction of monetary policy in some dominant economies have caused substantial risk facing emerging economies (Ai Ping \& Muthuveloo, 2015).

The global financial crisis and the consequential implications and effects on the business environment, whether internal or external, constitute one of the most important topics in contemporary research, although analysts are unable to determine their precise causes and sources. While companies face the inevitable risks of the crisis and its consequences that threaten, in some cases, their survival and continuity if not responded to and adapted to. Since the crisis broke out in September 2008, its repercussions and consequences have affected the Jordanian economy in all its sectors (Matar \& Nuaimat, 2014). The most significant manifestation of these repercussions was the sharp drop in the profits of the Jordanian public shareholding companies listed on the Amman Stock Exchange in 31/12/2008, with all sectors reaching an average drop rate of $48 \%$. This decline was reflected in the trading volumes of those companies, which also fell by $62 \%$. On average, this effect extends to its market values, which fell by an average of 55\% (Burghol, 2015); in other words, the wider business and management implications of having or not having a system of ERM should be considered. Forces such as globalization and instability in the political and economic environment add complexity to business and have provided a significant impetus to the importance of managing risks. Internationally, the financial crisis of 2008 has highlighted some weaknesses in the process of risk management (Voinea \& Anton, 2009).

In the context of the Middle East, the events of the Arab Spring have increased the risk perceptions of organizations (Al Khattab \& Hood, 2015). Previous risk management studies on Jordanian organizations (Khattab, Anchor, \& Davies, 2008) reported that risk assessment practice is crisis-oriented. Risk management is not fully integrated into the general business and management decision-making process, in that it focuses only on the negative outcomes of possible events and not on the balance between risk and reward. ERM is seen as a top down approach, which constitutes identifying, assessing, and responding to strategic, operational, and financial risks in order to achieve four objectives: strategy (high level goals that align with company mission), operations (effective and efficient use of resources), reporting (reliability of reporting), and compliance (compliance with applicable laws and regulations) (Harner, 2010). ERM is believed to have positive impact on firm's performance (Shad, Lai, Iskandar, 2015). Therefore, this study sought to determine the relationship between enterprise risk management and institutional performance in public shareholding companies in the southern region of Jordan.

\section{Literature Review \\ Risk and Risk Management}

The term "risk management" is an open-concept that has no specific fixed agreed definition. Every specialist in this area has its own definition of the concept, based on his personal experience and the experience and culture of the organization, which works to manage risks (Abdel-Hay, 2010). Risk management is a continuous process of making and implementing decisions that will minimize the extent of uncertainty concerning exposure to risks that have an impact on the business - in other words, it is the natural tendency of the organization to balance between opportunities (Martin, 2013). In this regard risk management is a process affected by an entity's board of directors, management and other personnel, and is applied in strategy setting and across the enterprise, designed to identify potential events. In turn, it may affect the entity, and manage risk to be within its risk appetite and provide reasonable assurance of the achievement of the entity's objectives (Bujayrami, 2011). In a state of uncertainty, it is the probability of the occurrence of circumstances/events that could have an influence on the goals established, including the possibility of a loss or a profit based on the difference found in the desired result. Both risk and incident are associated with the possibility of the occurrence of the event causing the danger, and the related effects or consequences (AS/NZS, 2004). The common feature of many risk definitions is that risk deals with uncertainty (Ferkolj, 2010). One of the most general definitions of risk was provided by the International Organization for Standardization in the ISO 31000 standard. According to such standard, risk is defined as the effect of uncertainty on objectives (ISO, 2015). Similarly, Hopkin (2010) provided a comprehensive definition of the word risk in the business context and described a major risk to an organization as "an event with the ability to impact (inhibit, enhance or cause doubt about) the mission, strategy, project, routine operation, objective, core process, key dependencies and/or the delivery of 
stakeholder expectations. By the term uncertainty, we mean the absence of certainty or something, which is not known. It refers to a situation where there are multiple alternatives resulting in a specific outcome, but the probability of the outcome is not certain. This is because of insufficient information or knowledge about the present condition. Hence, it is hard to define or predict the future outcome or events. Uncertainty cannot be measured in quantitative terms through past models. Therefore, probabilities cannot be applied to the potential outcomes, because the probabilities are unknown (Surbhi, 2016). Risk management is a central part of any organization's management as it helps managers gain an understanding of the potential positive and negative effect of all the internal and external factors surrounding the organization, and thereby, increases the probability of achieving the organization's overall objectives.

\section{From Traditional Risk Management to Enterprise Risk Management}

In traditional risk management (TRM), the risk management process is often referred to as silobased, which relates to a single risk being isolated and dealt with individually. Silos occur when organizations view each type of risk as a standalone object and so they act on each risk independently from the other types of risk they face (Pagach \& Warr, 2010). This approach comes with some limitations, which among others, it is considered inconsistent in the way that it may lead to different treatment of similar risks (Lundqvist, 2013). Another important aspect is that the silo-based risk management approach does not take into account the interdependency between risks (Wihlborg, 2009). This is an important limitation for two reasons: the lack of understanding of risk and the unnoticed natural hedge, and managing risks one at a time makes the firm incapable of understanding the risk in-depth and the consequences of it (Lundqvist, 2013). Comparatively, enterprise risk management emphasizes a comprehensive view of risk and risk management, meaning that different risks within an organization should not be managed separately (Nia, et al., 2017). Rather than focusing solely on hazard or financial forms of risk, enterprise risk management seeks to address all events that might adversely or positively impact the performance of an organization. In other words, vast variety of risks should be treated in a holistic manner and the correlation of various risks should be analyzed (Tavakoli et al., 2016).

Enterprise Risk Management

The recession has forced businesses to place more focus on the management of risks relating to all aspects of their businesses. Such management is broadly defined as enterprise risk management (ERM), which describes the set of activities businesses undertake to deal with all the diverse risks that face them in a holistic, strategic and integrated method (Dafikpaku, 2011). In spite of its slow growth, ERM is becoming gradually vital for companies recently because of the increase risk and the need to reframe the structure of development of companies and firms (Martin, 2013).According to Brown, Steen and Foreman (2009), ERM is not only an approach and a process that organizations use to management risk, but also a chance to seek better opportunities, and achieve higher objectives. The main objective of ERM is to help management to deal with uncertainties and the associated risks and opportunities in the process of creating value (Eikenhout, 2015). A variety of ERM definitions can be found; for instance, COSO (2004) defined ERM as "a process, affected by an entity's BODs, management and other personnel, applied in strategy setting and across the enterprise, designed to identify potential events that may affect the entity, and manage risk to be within its risk appetite, to provide reasonable assurance regarding the achievement of entity objectives." Aside from this definition, Asian Risk Management Institute referred to ERM as "a disciplined and cohesive approach to risk that supports the configuration of strategy, process, people, and technology, and allows firms to categorize, rank, and effectively accomplish their serious risks (Ai, Teoh, Lee, \& Muthuveloo, 2017). Moreover, the Casualty Actuarial Society (CAS) describes Enterprise Risk Management as the discipline by which an organization in any industry assesses, controls, exploits, finances and monitors risk from all sources for the purpose of increasing the organization's short- and long-term value to its stakeholders." The overall purpose of ERM is to manage and mitigate risks and take advantage of opportunities at an enterprise level (Society of Actuaries, 2006).

\section{Enterprise Risk Management Framework}

The use of standards and frameworks is claimed to proactively improve organizational resilience and sustainability (RIMS, 2011). A risk management framework is described as "an organizational specific 
set of functional activities and the associated definitions that define the risk management system in an organization and also the relationship to the risk management organizational system" (Dafikpaku, 2011). Several ERM frameworks are currently being used. Although they are different in name, industry and region, they all share a common theme: the identification, prioritization and quantification of risks in order to help corporations effectively manage their exposure (Yazid, Hussin, \& Daud, 2011). The lack of a widely accepted ERM conceptual framework led the Committee of Sponsoring Organizations of the Treadway Commission (COSO), widely known for its Internal Control Integrated Framework (COSO, 1992), to initiate an effort to develop common terminology and an accepted framework for ERM.

In September 2004, COSO (2004) issued Enterprise Risk Management Integrated Framework, that provides a model of the ERM process (Beasley et al.,2006) In this regard, one of the most popular frameworks being implemented is the Committee of Sponsoring Organizations of the Treadway Commission (COSO). The foundation for the ERM methodology was based on COSO's 1992 Internal Control - Integrated Framework, a publication that formulated a uniform approach to managing internal control system (Yazid, Hussin, \& Daud, 2011). Based on the conducted survey "COSO's ERM Framework was overwhelmingly the most well-known of the frameworks with $36.7 \%$ of respondents reporting they were very familiar with the framework and only $7.9 \%$ of respondents indicating they were not at all familiar with the framework". In their COSO's 2010 Report on ERM, studies (Uwizeye, 2013; Beasley, 2010) found that when organizations looked for guidance in ERM implementation, they typically chose COSO's ERM framework (54.6\%) compared to other frameworks.

To provide companies a guideline in how to implement ERM, COSO developed a framework, known as the Enterprise Risk Management - Integrated Framework in 2004. This framework is an extension of the initial framework of 1994. The goal of ERM is to help achieve the organization's objectives (COSO, 2004). The eight ERM components, listed at the front of the cube, show what is needed to achieve these objectives. As was argued before, the goal of ERM is to help achieve an organization's objectives. This is done by handling all the risks in a holistic approach. This offers opportunities for companies to respond to their risks in alignment with their corporate strategy (Geessink, 2012). The COSO ERM Framework comprises a three-dimensional matrix in the form of a cube, which reflects the relationships between four objectives, eight components and four different organizational levels. The COSO ERM framework consists of eight components of ERM that are needed to help a firm achieve its objectives (COSO, 2004). All eight components need to be implemented and integrated to provide effective ERM. The framework emphasizes entity wide risk management across four objectives: strategic, operations, reporting, and compliance. It also emphasizes that risks are examined at each level of the organization (i.e., subsidiary, business units, division, entity) beginning with the entity level and aggregated across all levels so that a portfolio of risks can be managed holistically (Curkovic, Scannell, Wagner \& Vitek, 2013). COSO framework describes eight interrelated but different components of enterprise risk management, which are (Passenheim, 2010);

Internal Environment - The internal environment encompasses the tone of an organization and sets the basis for how risk is viewed and addressed by an entity's people, including risk management philosophy and risk appetite, integrity and ethical values, and the environment in which they operate.

Objective Setting - Objectives must exist before management can identify potential events affecting their achievement. Enterprise risk management ensures that management has in place a process to set objectives and that the chosen objectives support and align with the entity's mission and are consistent with its risk appetite.

Event Identification - Internal and external events affecting achievement of an entity's objectives must be identified, distinguishing between risks and opportunities. Opportunities are channeled back to management's strategy or objective-setting processes.

Risk Assessment - Risks are analyzed, considering likelihood and impact, as a basis for determining how they should be managed. Risks are assessed on an inherent and a residual basis.

Risk Response - Management selects risk responses - avoiding, accepting, reducing, or sharing risk - developing a set of actions to align risks with the entity's risk tolerances and risk appetite.

Control Activities - Policies and procedures are established and implemented to help ensure the risk responses are effectively carried out. 
Information and Communication - Relevant information is identified, captured, and communicated in a form and timeframe that enable people to carry out their responsibilities Effective communication also occurs in a broader sense, flowing down, across, and up the entity.

Monitoring - The entirety of enterprise risk management is monitored, and modifications made as necessary. Monitoring is accomplished through ongoing management activities, separate evaluations, or both.

Therefore, effective adoption of ERM in an organization may be used as a benchmark for other followers in ensuring the environment of workplace is free from risks and uncertainties. Finally, organizations are embracing ERM because it makes good business sense. Today, they actively make the decision to change the way they take risks. They implement innovative procedures, install new technology, and actively reshape their corporate culture to facilitate better risk taking. Implementing an effective strategy of ERM is not easy and for each organization, it is different (Setapa, 2015).

Balanced Scorecard (BCS)

In 1992, Robert Kaplan and David Norton introduced the Balanced Score Card, as a substitute for financial measures, to measure the financial and non-financial indicators within an integrated system and ultimately, to measure the strategic performance of the organizations (Tarawneh, 2011). Kaplan and Norton (1992) defined the BSC as a balanced measurement system, which provides top management of the organization with a quick, and yet comprehensive view of the organizational performance (Tanya, 2011). The BSC is a collection of measures, arranged in cards. The measures are related to four major managerial perspectives and have a comprehensive view of the business. In general, balanced scorecard merges business strategies into a comprehensive management system (Niknazar, 2011). In addition, BSC offers a solution to translate an organization's mission and strategy into a comprehensive set of performance measures that provide a framework for a strategic measurement and management system with four interrelated perspectives: financial, customer, internal processes, and employee learning and growth. The initial model provided a balance between short- and long-term objectives, between financial and non-financial measures, between leading and lagging indicators, and between external and internal performance perspectives (Kaplan \& Norton, 1992). The accuracy of BSC is the result of its non-financial measurements (customer satisfaction, internal business processes, and opportunities for learning and growth) and its financial measurements.

In relation to the above, financial measures convey the economic consequences of the actions already taken by the organization and focus on the profitability related measures on which the shareholders verify the profitability of their investment. Under this perspective the most common performance measures incorporated are: ROI, Cash Flow, Net Operating Income, Revenue Growth, among others (Sabah \& Khawla, 2012). Customer perspective captures the ability of the organization to provide quality goods and services, the effectiveness of their delivery, and overall customer service and satisfaction. This is the result of the cumulative function of price, quality, availability, selection, functionality, service, partnerships and brand value propositions, which will lead to increased customer acquisition and retention (Kairu, 2013).

Moreover, internal business processes are the mechanisms through which organizational performance expectations are achieved. Customer-based measures are important, but they must be translated into measures of what the organization must do internally to meet its customers' expectations. Therefore, managers need to prioritize critical internal operations (Sabah \& Khawla, 2012) that enable them to satisfy customer needs (Cheruiyot, 2013). The central theme of this perspective is the results of the internal business processes, which lead to financial success and satisfied customers. Typically, the measures of this perspective are based on producing goods and services in the most efficient and effective methods. Commonly used measures for this perspective are cost of quality, cost of non-conformance, process innovation, time saving and others.

Moving on to the learning and growth perspective, it is a dimension that identifies the infrastructure that the organization must adopt for creation, improvement and long-term growth. This dimension considers the ability of staff, the quality of information systems and the impact of coordination within the organization in supporting organizational objectives. This dimension focuses on employee satisfaction, retaining, and training them (Maraghi, 2012). More specifically, the perspective is related to 
the employees of the organization, and it measures the extent to which the organization exerts efforts to provide its employees with opportunities to grow and learn in their domain. Kaplan and Norton acknowledged that the learning and growth measures are the most difficult to select; therefore, they suggested the following measures as examples - employee empowerment, employee motivation, employee capabilities, and information systems capabilities (Al-Najjar \& Kalaf, 2012).

Enterprise Risk Management and Performance

The performance of a firm is crucial to indicate whether a firm is facing loss or profit. Business performance is often a key concept and the main concern of strategic management (Ai Ping \& Muthuveloo, 2015). A commonly agreed view is that an effective implementation of ERM enables improved performance (Kommunuri, Narayan, Wheaton \& Jandug, 2009). Therefore, implementation of an effective ERM should result in higher firm performance (Malik, 2017). ERM consists of methods and processes through which organizations manage risks and capture opportunities consistent with their strategic objectives. It assists the board of directors by ensuring that management is actively identifying and evaluating risks through standardized processes, which help in making informed decisions. According to Brown, Steen \& Foreman, (2009), effective ERM processes will result in ensuring fewer surprises, assisting management and exploitation of opportunities, enhancing information processing and communication, increasing firm reputation, enhancing organizational stature of accountability, assurance and governance, and contributing to overall planning and firm performance. They further explained that an ERM approach should encourage disclosures of risk related issues to the board of directors, which in turn, promotes transparency and better management of the business.

Nevertheless, most of the previous studies that evaluated value creation of ERM only focused on the financial aspect of firm performance (Hoyt \& Liebenberg, 2011; Izah, Tahir \& Ahmad, 2011; Gordon, Loeb \& Tseng, 2009). According to Acharyya and Mutenga (2013), there are other stakeholders in the firm besides shareholders (e.g., customers, governance, social environment, etc.). Most notably in the financial sector, (particularly banking and insurance) customers, employees, government and social responsibilities are integral components and based on the statement of many authors (e.g., COSO Executive Summary, 2004; Acharyya \& Mutenga, 2013; Arena, Arnaboldi \& Azzone, 2010; Nocco \& Stulz, 2006), all of the organization significant and critical risks cannot be related to capital and finance.

\section{Research Methodology}

Research design is a way to systematically solve the research problem (Kothari, 2004). This study adopted descriptive research design for the purpose of accessing the study's general intent. This design involves a set of methods and procedures that describe the intended variables using statistical logic. The researcher also adopted information from primary sources to obtain the required data, by using of field survey of data collection and statistically analyzing data to test the validity of hypotheses, and to answer questions. Also, information from secondary sources was obtained from previous studies, books and published researches in journals and scientific journals and statistics, and websites, in order to build a theoretical framework for the study.

The study population is composed of supervisory staff at the level of manager, deputy director, and head of department, numbering 382 in extractive companies in the south of Jordan. These include, Jordan Cement Factories Company, Jordan Phosphate Company, and Arab Potash Company. These companies were selected as they are the oldest and the most important three extractive companies in Jordan. Eight components are used to measure ERM implementation in this study, and they are considered as the independent variables - internal environment (5 items), objective setting (4items), event identification (4 items), risk assessment (4 items), risk response (4 items), control activities (4 items), information and communication ( 3 items) and monitoring ( 3 items). These items are adapted from Altemayer (2004) based on components of COSO (2004). The survey questionnaire was basically adapted by considering prior research works (i.e., Beasley, Clune, \& Hermanson, 2006; Jwana, 2014; Al-Khadash, 2017). Institutional performance is considered in this study as the dependent variable and is measured by balance scorecard with the following perspectives; financial perspective (4 items), customer perspective (5 items), internal business process perspective (5 items), and learning and growth perspective (5 items). These items were adopted from prior authors' works (Abdulsattar, 2016; Ashour, 2015; Haseena, 2015), gauged using a five scale questionnaire. Thus, the researcher is confident that the methodology adopted 
provides a reasonable theoretical basis for assessing the extent of ERM implementation in Jordanian Public Shareholding Companies.

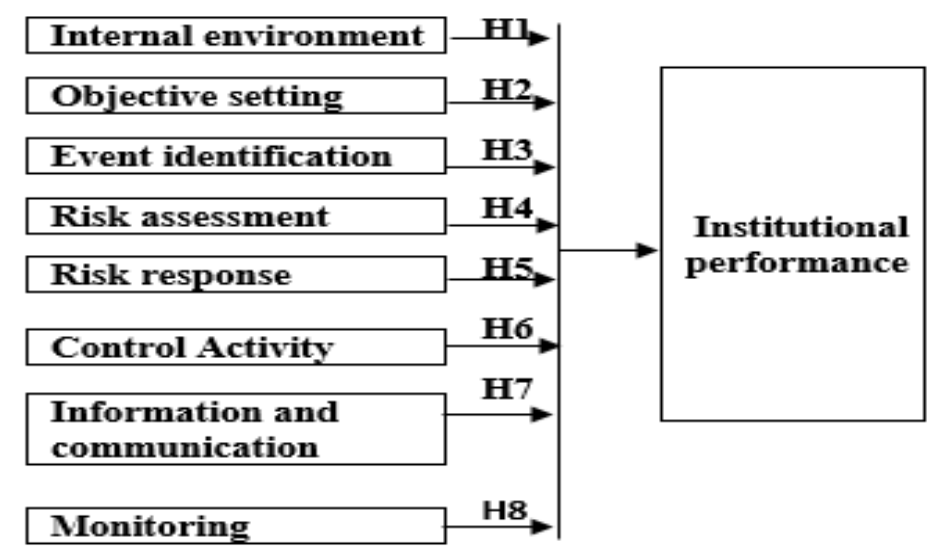

Research model

Figure 3.1 research model

Findings and Analysis

Over 313 collected questionnaires, 294 useful responses were received from the male $(93.9 \%)$ and 19 from the female respondents $(6.1 \%)$. Therefore, the sample of this study is dominated by male respondents. Responders were asked to specify their qualification as a result of which, $86.3 \%$ of the respondents held bachelor's degrees, 6.1\% held master's degrees, 5.4\% held $\mathrm{PhD}$ and $2.2 \%$ held Diploma. In specifying the work experience of the respondents, $84.7 \%$ of them had more than 15 years of work experience, $9.3 \%$ of them had $10-15$ years of work experience, $4.2 \%$ had $5-10$ years of work experience and $1.9 \%$ had less than 5 years of work experience. Finally, the respondents were asked to specify their job position. As a result, $69.9 \%$ of them were head of departments, $23.6 \%$ were directors and $6.7 \%$ were deputy directors. In the structural model, the direct effects of Internal Environment (IE), Objective Setting (OS), Event Identification (EI), Risk Assessment (RA), Risk Response (RR), Control Activities (CA), Information and Communication (IC) and Monitoring (MN) as independent variables on Institutional Performance (IP) as dependent variable were examined (i.e., H1, H2, H3, H4, H5, H6, H7 and H8 respectively). Furthermore, direct effects of the variables of the structural model were tested and the answers are summarized in Figure 1. The Smart-PLS model for direct effects is portrayed in the next figure. 


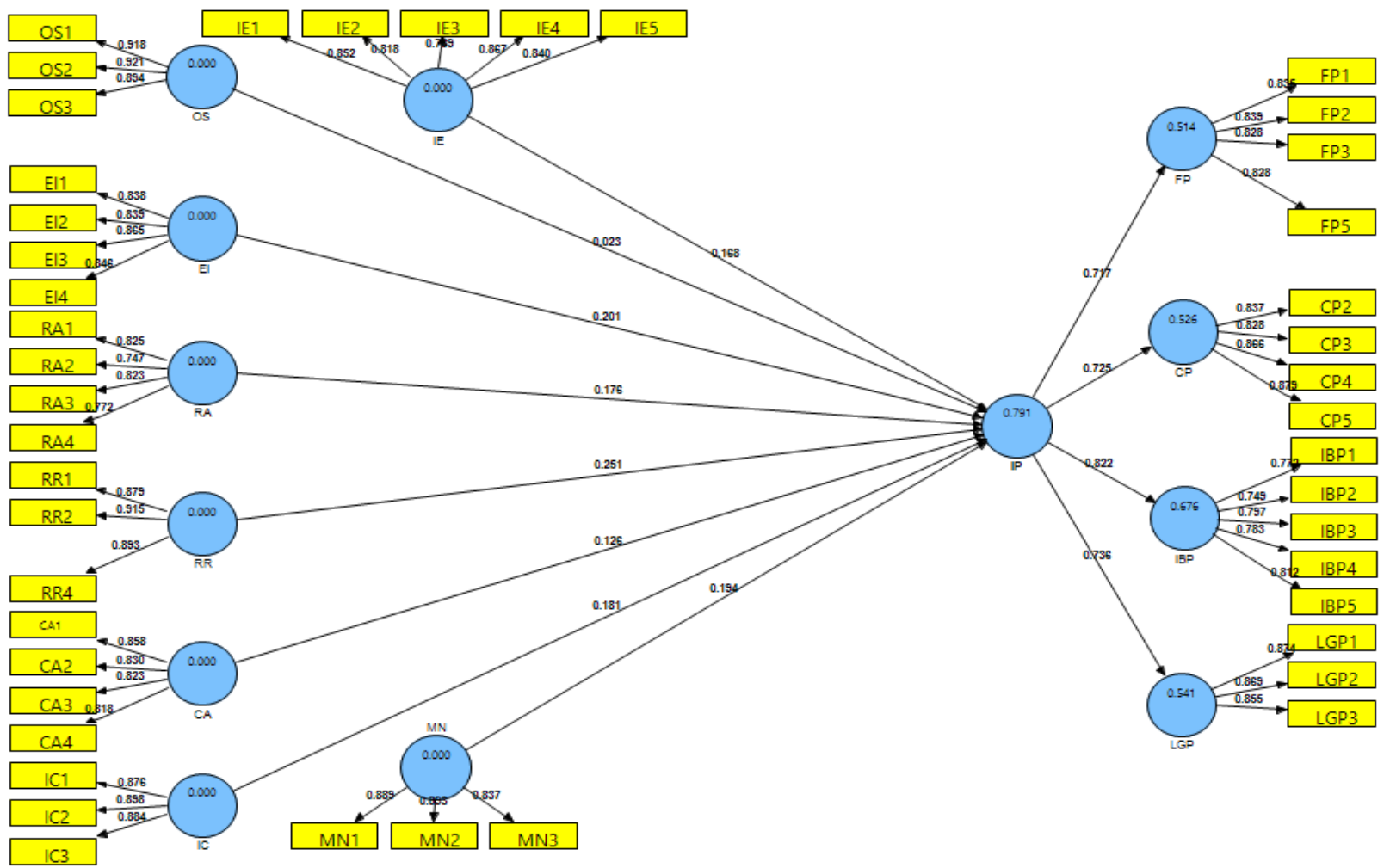

Figure 4.1 PLS Analysis of the Structural Model for Direct Effects

The value of R2 for Institutional Performance (IP) was 0.791. This indicates 79 percent of variations in Institutional Performance (IP) are explained by its eight predictors (i.e., IE, OS, EI, RA, RR, $\mathrm{CA}, \mathrm{IC}$ and $\mathrm{MN}$ ). Overall findings showed that the $\mathrm{R}^{2}$ value satisfies the requirement for the 0.30 cut off value as recommended by Quaddus and Hofmeyer (2007). The value of Q2 for Institutional Performance (IP) was 0.443 , far greater than zero, which confirms the predictive relevance of the model as suggested by Chin 2010. In sum, the model exhibits acceptable fit and high predictive relevance.

The coefficient parameters estimates were then examined to test the hypothesized direct effects of the variables, the results of which are tabulated in Error! Reference source not found.1. The path coefficients and the results of examining hypothesized direct effects are displayed in Table 2.

\begin{tabular}{llllll}
\hline Path Shape & Path Coefficient & Standard Error & T-value & P-value & Hypothesis Result \\
\hline IE $\rightarrow$ IP & $0.168^{* * * *}$ & 0.039 & 4.281 & 0.000 & H1) Supported \\
OS $\rightarrow$ IP & 0.023 & 0.026 & 0.868 & 0.386 & H2) Rejected \\
EI $\rightarrow$ IP & $0.201^{* * *}$ & 0.033 & 6.006 & 0.000 & H3) Supported \\
RA $\rightarrow$ IP & $0.177^{* * *}$ & 0.030 & 5.809 & 0.000 & H4) Supported \\
RR $\rightarrow$ IP & $0.251^{* * *}$ & 0.027 & 9.379 & 0.000 & H5) Supported \\
CA $\rightarrow$ IP & $0.126^{* * *}$ & 0.033 & 3.815 & 0.000 & H6) Supported \\
IC $\rightarrow$ IP & $0.181^{* * *}$ & 0.031 & 5.875 & 0.000 & H7) Supported \\
MN $\rightarrow$ IP & $0.194^{* * *}$ & 0.029 & 6.799 & 0.000 & H8) Supported \\
\hline
\end{tabular}

Table 4.2 Examining Results of Hypothesized Direct Effects 
H1 proposed that Internal Environment (IE) has a positive effect on Institutional Performance (IP). Result after analysis shows that $t$-value and p-value of Internal Environment (IE) in predicting the Institutional Performance (IP) were 4.281 and 0.000 respectively. Thus, H1 was supported. The path coefficient was 0.168 , indicating a positive relationship. It means, when Internal Environment (IE) goes up by 1 standard deviation, Institutional Performance (IP) will go up by 0.168 standard deviations. This result is supported by prior studies (Ai Ping \& Muthuveloo, 2015; Jwana, 2014; Al-Khadash, 2017). In H2, Objective Setting (OS) was found to have a positive but insignificant effect on Institutional Performance (IP); path coefficient $=0.023, \mathrm{t}$-value $=0.868, \mathrm{p}$-value $=0.386$. Thus, $\mathrm{H} 2$ was rejected. This insignificant relationship can be attributed to the fact that the companies may not have established high levels of goals consistent with their mission and vision. Also, management may not have considered the impact of risks related to strategic options, and performance measures were inconsistent to ensure that actual results fall within the level of risk that the company accepts. This result contradicts with the previous findings of some authors (e.g., Liebenberg \& Hoyt, 2003; Beasley et al., 2005; Pagach \& Warr, 2011) but is consistent with others (e.g., Rao et al., 2007; Alawattegama, 2017). Moving on to H3, it proposed that Event Identification (EI) has a positive effect on Institutional Performance (IP) and the result after analysis showed that the $\mathrm{t}$-value and p-value of Event Identification (EI) in predicting the Institutional Performance (IP) were 6.006 and 0.000 respectively. Thus, H3 was supported. The path coefficient was 0.201, indicating a positive relationship. It means, when Event Identification (EI) goes up by 1 standard deviation, Institutional Performance (IP) will go up by 0.201 standard deviations. This result is supported by past studies (e.g., Teoh, Lee \& Muthuveloo, 2017; Karimi, 2014; Tavakoli \& Abu Talib, 2014).

Moreover, H4 proposed that Risk Assessment (RA) has a positive effect on Institutional Performance (IP). Result after analysis showed that the t-value and p-value of Risk Assessment (RA) in predicting the Institutional Performance (IP) were 5.809 and 0.000 respectively. Thus, H4 was supported. The path coefficient was 0.177, indicating a positive relationship. It means, when Risk Assessment (RA) goes up by 1 standard deviation, Institutional Performance (IP) will go up by 0.177 standard deviations This result is supported by prior studies (e.g., Oppong, et al., 2016; Ibrahim, et al.,2017).

Meanwhile, in H5, it was proposed that Risk Response (RR) has a positive effect on Institutional Performance (IP). Result after analysis showed that the t-value and p-value of Risk Response (RR) in predicting the Institutional Performance (IP) were 9.379 and 0.000 respectively. Thus, H5 was supported. The path coefficient was 0.251 , indicating a positive relationship. It means, when Risk Response (RR) goes up by 1 standard deviation, Institutional Performance (IP) will go up by 0.251 standard deviations. This result is supported by past studies (e.g.,Beasley et al., 2005; Al-Khadash, 2017; Jwana, 2014). In H6, it was proposed that Control Activities (CA) has a positive effect on Institutional Performance (IP). Result after analysis showed that the t-value and p-value of Control Activities (CA) in predicting the Institutional Performance (IP) were 3.815 and 0.000 respectively. Thus, H6 was supported. The path coefficient was 0.126, indicating a positive relationship. It means, when Control Activities (CA) goes up by 1 standard deviation, Institutional Performance (IP) will go up by 0.126 standard deviations. This result is also supported by related studies in literature (Tuan \& Hung, 2015; Asiligwa \& Rennox, 2017).

Furthermore, H7 proposed that Information and Communication (IC) has a positive effect on Institutional Performance (IP). Result after analysis showed that the $\mathrm{t}$-value and p-value of Information and Communication (IC) in predicting the Institutional Performance (IP) were 5.875 and 0.000 respectively. Thus, $\mathrm{H} 7$ was supported. The path coefficient was 0.181 , indicating a positive relationship. It means, when Information and Communication (IC) goes up by 1 standard deviation, Institutional Performance (IP) will go up by 0.181 standard deviations. This result is supported by studies done by Ai and Teoh (2017), Jwana (2014) and Tavakoli and Abu Talib (2014). Finally, H8 proposed that Monitoring $(\mathrm{MN})$ has a positive effect on Institutional Performance (IP). Result after analysis showed that the $t$-value and p-value of Monitoring (MN) in predicting the Institutional Performance (IP) were 6.799 and 0.000 respectively. Thus, H8 was supported. The path coefficient was 0.194 , indicating a positive relationship. It means, when Monitoring (MN) goes up by 1 standard deviation, Institutional Performance (IP) will go up by 0.194 standard deviations. This result is supported by past studies (Njoki, 2015; Jwana, 2014; AlKhadash, 2017). 


\section{Conclusion}

Implementation of ERM is considered at its infancy stage in Jordan. This study concludes the importance and presence of awareness of ERM implementation among Jordanian public shareholding companies. This awareness of ERM can be traced back to 2008 after the financial crises, as few respondent companies have already adopted the system within the organization at the time of this study. Jordanian public shareholding companies and government have realized that the importance of ERM in managing the business risks in a holistic way could help the firm to identify the events at the preliminary stage, to reduce the unnecessary negative surprise and to respond to the changes, internally or externally, which might threaten the firm's performance and create harm to the shareholders' value.

The objective of this study was to empirically verify the implementation of ERM framework, suggested by the COSO's ERM integrated framework, and its impact on institutional performance. This study found that seven out of the eight components of framework suggested by the COSO's ERM integrated framework has a significant impact on institutional performance. These components are Internal Environment, Event Identification, Risk Assessment, Risk Response, Risk Response, Information and Communication, and Monitoring. The eighth component, which is objective setting, was found to have an insignificant impact on institutional performance so companies should pay more attention to the objective setting process and make it consistent with their vision and mission. They should also consider the risks associated with the strategic options that affect the company. Surprisingly, prior empirical evidence revealed that objective setting, of ERM framework, have a positive impact on the performance, but not in the context of Jordanian public shareholding companies. Based on the empirical evidences, this study concludes that the implementation of ERM has a positive impact on the institutional performance of Jordanian public shareholding companies. The findings of this study are consistent with the theoretical expectations that the adoption of ERM practices has a positive impact on firm performance confirmed by previous relevant studies (Beasley, 2008; Hoyt \& Liebenberg, 2011; Pagach \& Warr, 2010; Ai Ping \& Muthuveloo, 2015; Jwana, 2014).

In terms of implications to the public shareholding companies in Jordan, such companies should employ robust enterprise risk management practices owing to their positive influence on their performance. In addition, for the public shareholding companies to improve on their institutional performance, they should focus more on improving objective setting as this may have a role in enhancing such performance type. Specifically, companies should set high levels of goals consistent with the mission and vision of the company. Management should consider the impact of risks related to strategic options and the performance metrics must be consistently maintained to ensure that actual results fall within the level of risk that the company accepts. Lastly, the study recommends the creation of a Specialized Committee to conduct a frequent evaluation of the enterprise risk management measures put in place by the public share holding companies in Jordan and reward those with excellent practices. This will encourage more firms to institute ERM practices as well as create more awareness on the need for the same in all organisations.

In terms of the limitations, the researcher faced several problems including those during the data collection, where the managers and other respondents failed to provide the much-needed information because they believe this information is confined to top management confidentiality. To solve those problems, the researcher explained to the respondents that the survey is confidential and that the work is designed to yield a better outcome and that information is used for scientific research only. There is limited research conducted in the field of ERM in Jordan in economic sectors. This can be attributed to the fact that the implementation of ERM framework is not mandatory by any Jordanian regulatory agency and the need and significance of such framework is not communicated, as it should be .Other limitations faced by the researcher include the varying locations of the companies, which made it difficult for the researcher to personally visit them. Also, because the three companies surveyed are one of the largest and oldest companies in Jordan and owing to their sizes, it was difficult to obtain the right respondents in different departments of the companies, to answer the questions.

This research opened a lot of research opportunities in the field of enterprise risk management, particularly in the implementation of enterprise risk management frameworks and institutional performance in Jordan, and in terms of the balance scorecard for measuring performance. This study 
presented some empirical evidence based on the extraction companies in the southern region of Jordan, and in this respect, there is a need for further studies to be carried out in a different environment with unique characteristics. This would assist to establish a wider generalizability of the findings of the study. It would further give greater value and usefulness to the findings of the study and their generalizability. This study used the COSO 2004 Framework for Enterprise Risk Management, so the researcher recommends using the COSO 2017 Enterprise Risk Management Framework while examining its impact on performance

That said, future researches should also weigh upon corporate governance as a moderator for more studies. This study was conducted on extractive companies in southern Jordan. Based on the results of this study, it is recommended that further studies should be conducted on the industrial companies listed on the Amman Stock Exchange. This study employed quantitative research method, with the survey questionnaire as the only instrument used to collect data. Perhaps future research should employ a qualitative method, which includes interviews to elicit verbal descriptions of characteristics, cases and setting.

\section{References}

Acharyya, M., \& Mutenga, S. (2013). The benefits of implementing enterprise risk management: evidence from the non-life insurance industry. Enterprise Risk Management, 6(1), 22-24.

Arena, M., Arnaboldi, M., \& Azzone, G. (2010). The organizational dynamics of enterprise risk management. Accounting, Organizations and Society, 35(7), 659-675.

Asiligwa, M. and Rennox, G. (2017) 'The Effect of Internal Controls on the Financial Performance of Commercial Banks in Kenya', IOSR Journal of Economics and Finance, 8(3), pp. 92-105. doi: 10.9790/5933-08030492105.

Ashour, Hossam Abdel Karim. (2015). the use of Balanced Scorecard (BSC) as a tool to measure the performance of Palestinian hospitals in the Gaza Strip. Unpublished thesis, Academy of Management and Politics for Postgraduate Studies

Alawattegama, K. K. (2017). The Impact of the Adoption of Enterprise Risk Management on the Industrial Financial Performance. International Journal of Research in Business and Social Science (2147-4478), 6(6), 9-20.

Al-Khadash, H. A., Jireis, J. R, (2017). COSO Enterprise Risk Management Implementation in Jordanian Commercial Banks and its Impact on Financial Performance.

Al Khattab, A., \& Hood, J. (2015). The risk management process in Jordanian public shareholding organisations. International Journal of Business and Management, 10(8), 151.

Alshammari, A. M. (2011). The evaluation of the impact of using balanced scorecard on strategic performance in small and medium enterprises.

Beasley, M. S., Clune, R., \& Hermanson, D. (2006). The impact of enterprise risk management on the internal audit function (Vol. 8113). Kennesaw, GA: Digital Commons@ Kennesaw State University.

Beasley, M. S., Clune, R., \& Hermanson, D. R. (2005). Enterprise risk management: An empirical analysis of factors associated with the extent of implementation. Journal of accounting and public policy, 24(6), 521-531.

Brown, I., Steen, A., \& Foreman, J. (2009). Risk management in corporate governance: A review and proposal. Corporate Governance: An International Review, 17(5), 546-558.

COSO - Executive Summary (2004) 'Enterprise Risk Management - Integrated Framework', New York, 3(September), pp. 1-16. doi: 10.1504/IJISM.2007.013372.

Curkovic, S., Scannell, T., Wagner, B., \& Vitek, M. (2013). A longitudinal study of supply chain risk management relative to COSO's enterprise risk management framework. Modern Management Science \& Engineering, 1(1), 13-36.

Cheruiyot, S. K. (2013). An Investigation into Factors Affecting Implementation of The Balanced Score Card in State Corporations in Kenya: A Case Study of Kenya Bureau of Standards (Doctoral dissertation, The Open University of Tanzania).

Dafikpaku, E., Eng., M. B. A. B., \& Mcmi, M. (2011, March). The strategic implications of enterprise risk management: a framework. In ERM Symposium (Vol. 48).

Eikenhout, L. C. A. (2015). Risk management and performance in insurance companies (Master's thesis, University of Twente).

Gatzert, N., \& Martin, M. (2015). Determinants and value of enterprise risk management: empirical evidence from the literature. Risk Management and Insurance Review, 18(1), 29-53.

Gordon, L. A., Loeb, M. P., \& Tseng, C. Y. (2009). Enterprise risk management and firm performance: A contingency perspective. Journal of Accounting and Public Policy, 28(4), 301-327. 
Harner, M. M. (2010). Barriers to effective risk management. Seton Hall L. Rev., 40, 1323.

Haseena, Q. (2015) 'The role of knowledge management in improving institutional performance. unpublished thesis, Mohammed Khaydar University - Biskra -.

Hoyt, R. E., \& Liebenberg, A. P. (2011). The value of enterprise risk management. Journal of risk and insurance, 78(4), 795-822.

Ibrahim, S., Diibuzie, G., \& Abubakari, M. (2017). The Impact of Internal Control Systems on Financial Performance: The Case of Health Institutions in Upper West Region of Ghana. International Journal of Academic Research in Business and Social Sciences, 7(4), 684-696.

Jwana, J. (2014) 'The Extent of Implementation of Risk Management Practices in Jordanian Commercial Banks and its Impact on Financial Performance. Unpublished thesis, Hashemite University

Kairu, E. W (2013) 'Effects of balanced scorecard on performance of firms in the service sector', European Journal of Business and Management, 5(9), pp. 81-88. Available at: http://www.iiste.org/Journals/index.php/EJBM/article/view/5127.

Kothari, C. R. (2004). Research methodology: Methods and techniques. New Age International.

Liebenberg, A. P., \& Hoyt, R. E. (2003). The determinants of enterprise risk management: Evidence from the appointment of chief risk officers. Risk Management and Insurance Review, 6(1), 37-52.

Malik, M. F. (2017). Enterprise risk management and firm performance: Role of the risk committee (Doctoral dissertation, Queensland University of Technology).

Maraghi, D. (2012) 'The Role of Human Resources Management Policies in Improving Institutional Performance: An Applied Study on Jordanian Public Institutions.

Matar, M., \& Nauimat, Z. (2014). The response of the boards of directors in the distressed Jordanian public shareholding companies to the risk and repercussions of the global financial crisis. Jordan Journal of Business Administration, 10(1), 18-44.

Niknazar, P. (2011). Evaluating the use of BSC-DEA method in measuring organization s efficiency.

Njeri, C. K. (2015). Effect of internal controls on the financial performance of manufacturing firms in Kenya. Unpublished Thesis.

Nocco, B. W., \& Stulz, R. M. (2006). Enterprise risk management: Theory and practice. Journal of applied corporate finance, 18(4), 8-20.

Nyagah, B. K. (2014). The effect of enterprise risk management on financial performance of pension fund management firms in Kenya. Unpublished, University of Nairobi.

Oppong, M., Owiredu, A., Abedana, V., \& Asante, E. (2016). The impact of internal control on the performance of faith-based NGOs in Accra. Available at SSRN 2803451.

Pagach, D., \& Warr, R. (2011). The characteristics of firms that hire chief risk officers. Journal of risk and insurance, 78(1), 185-211.

Passenheim, O. (2010). Enterprise risk management. Bookboon.

Ping, T. A., \& Muthuveloo, R. (2015). The impact of enterprise risk management on firm performance: Evidence from Malaysia. Asian Social Science, 11(22), 149.

Quaddus, M., \& Hofmeyer, G. (2007). An investigation into the factors influencing the adoption of B2B trading exchanges in small businesses.

Rao, A., \& Marie, A. (2007). Current Practices of Enterprise Risk Management in Dubai. Management accounting quarterly, 8(3).

Risk and Insurance Management Society (2011) 'An overview of widely used risk management standards and guidelines.

Robert, K., \& David, N. (1992). The balanced scorecard measures that drive performance. Harvard Organizational business Rev., 70: 71-79. Stalk, G., (1988). Time the next source of competitive advantage. Harvard Bus. Rev, 66, 41-51.

Sabah .M, A.-N. \& Khawla .H, K. (2012) Designing a Balanced Scorecard to Measure a Bank's Performance: A Case Study', International Journal of Business Administration, 3(4), pp. 44-53. doi: 10.5430/ijba. v3n4p44.

Setapa, M., Zakuan, N., Saman, M. Z. M., Ariff, M. S. M., Zaidin, N., \& Sulaiman, Z. (2015, March). The Impact of Enterprise Risk Management Practices on Malaysian Public Higher Educational Institution Performance: A Literature Review. In 2015 International Conference on Industrial Engineering and Operations Management (IEOM) (pp. 1-7). IEEE.

Shad, M. K., \& Lai, F. W. (2015). Enterprise risk management and firm performance validated through economic value-added factors. International Journal of Economics and Statistics, 3, 148-154.

Shannak, H. (2010) 'the Impact of Enterprise Risk Management on Performance: The Case of Jordanian Industrial Corporations. Unpublished thesis. Jordan University.

Shoter, M. (2016) The Determinants of Enterprise Risk Management and Its Effect on Firm's Value: Evidence from Firms listed in Amman Stock Exchange. Unpublished thesis, Yarmouk University. 
Society of Actuaries (2006) ‘Enterprise Risk Management Specialty Guide’, (May), pp. 1-60.

Tarawneh, A. (2011) 'Impact of investment in intellectual capital on institutional performance: A field study of Jordanian public institutions.

Tavakoli, S., \& Talib, N. A. (2014). A Comprehensive Approach to Relationship between COSO ERM and Firm Performance in Construction Industry. International Research Journal of Applied and Basic Sciences. Vol, 8(12), 2214-2220.

Tahir, I. M., \& Razali, A. R. (2011). The Relationship between enterprise risk management (ERM) and firm value: Evidence from Malaysian public listed companies. International journal of economics and management sciences, $1(2), 32-41$.

Teoh, A. P., Lee, K. Y., \& Muthuveloo, R. (2017). The Impact of Enterprise Risk Management, Strategic Agility, and Quality of Internal Audit Function on Firm Performance. International Review of Management and Marketing, 7(1), 222-229.

Tuan, N., \& Hung, D. N. (2015, May). A Theoretical Model Studying the Impact of Internal Control on Performance and Risks of Vietnam Commercial Banks. In International Conference on Accounting. Danang, Vietnam (Vol. 22).

Uwizeye, P. B. (2013). Enterprise-wide risk management (EWRM): identification, analysis and management of implementation barriers within an African telecommunications enterprise (Doctoral dissertation, Heriot-Watt University).

Voinea, G., \& Anton, S. G. (2009). Lessons from the current financial crisis. A risk management approach. Review of Economic and Business Studies, 3, 139-147.

Yazid, A. S., Hussin, M. R., \& Daud, W. N. W. (2011). An examination of enterprise risk management (ERM) practices among the government-linked companies (GLCs) in Malaysia. International Business Research, 4(4), 94. 